\title{
A comunicação interna como um instrumento de promoção da qualidade: estudo de caso em uma empresa global de comunicação
}

\section{Internal communication as a marketing tool to quality promotion: case study in a global communication company}

\author{
Lilian Maria de Souza Almeida ${ }^{1}$ \\ Luiz Gonzaga Mariano de Souza ${ }^{1}$ \\ Carlos Henrique Pereira Mello ${ }^{1}$
}

\begin{abstract}
Resumo: Apesar da ampla adoção pelas organizações de sistemas e modelos de gestão da qualidade mundialmente reconhecidos, pouca atenção ainda tem sido dada às práticas de comunicação interna que podem contribuir para a promoção da qualidade. Para se tornarem comprometidos com a entrega de produtos e serviços de qualidade, os membros de uma organização precisam receber informações, que lhes permitam entender e aceitar seus papéis individuais e coletivos nesse processo, exigindo, portanto, comunicação. O artigo busca a compreensão de como a comunicação interna pode ser utilizada como um instrumento de promoção da qualidade. A pesquisa foi conduzida pelo método estudo de caso, contando com a contribuição de uma empresa global de comunicação. Os resultados alcançados permitiram a identificação e a proposição de um conjunto de fatores a serem considerados pelas organizações como determinantes para a efetiva utilização da comunicação interna como um instrumento de promoção da qualidade, com destaque para: segmentação do público interno; coerência da linguagem; utilização estratégica de recursos visuais; comunicação de resultados; desenvolvimento de uma cultura da qualidade e compreensão da comunicação interna sob uma abordagem processual.
\end{abstract}

Palavras-chave: Comunicação interna. Qualidade. Promoção da qualidade.

\begin{abstract}
Despite the wide adoption of quality management systems and standards recognized all over the world by organizations, little attention has been given to internal communication practices which may contribute to an organization's quality promotion. If an organization wants its members to commit to the delivery of good quality products and services, the individuals must receive information that enables them to understand and accept their individual and collective roles in this process. This research seeks to understand how internal communication can be utilized as a quality promotion instrument. The investigation was conducted through the case study method with the contribution of a global communication company. The results obtained enabled the identification of the combined determinant factors to be considered in the use of internal communication as a quality promotion instrument, with proposals focused on: segmentation of internal public; language coherence; strategic use of visual resources; results communication; development of a quality culture, and the understanding of internal communication as a process.
\end{abstract}

Keywords: Internal communication. Quality. Quality promotion.

\section{Introdução}

Em resposta às diversas pressões por maior competitividade, cresce progressivamente o número de organizações de diferentes setores que vêm adotando os principais sistemas e modelos de gestão da qualidade utilizados no mundo (MOHR-JACKSON, 1998; NAVEH; MARCUS, 2005; PINTO et al., 2006; STEVENSON; BARNES, 2002). No entanto, a adoção desses sistemas e modelos, bem como qualquer esforço para a melhoria da qualidade nas organizações, depende, entre outros fatores, do comprometimento de seus funcionários. Segundo Palmer e Wilson (1995), o comprometimento requerido para o sucesso da gestão pela qualidade total deve ser inicialmente promovido na alta liderança para então ser disseminado em todos os outros níveis de uma organização. Esses autores também propõem um modelo, em que o

\footnotetext{
${ }^{1}$ Universidade Federal de Itajubá - UNIFEI, Av. BPS, 1303, Bairro Pinheirinho, CEP 37500-903, Itajubá - MG, Brasil,

E-mails: lilian.almeida@etep.edu.br; gonzaga@unifei.edu.br; carlos.mello@unifei.edu.br
} 
comprometimento é o fator que deve direcionar outros quatro elementos importantes para a implementação da qualidade total: desenvolvimento de equipes, treinamento, sistemas e comunicação.

Thornhill et al. (1996), além de darem destaque à relação entre comprometimento e qualidade, abordam o papel da comunicação na conquista desse comprometimento. De acordo com esses autores, a comunicação tem sido vista como um elemento-chave, entre as estratégias organizacionais utilizadas para promover o comprometimento com a qualidade.

Para que os funcionários de uma organização se tornem comprometidos com a entrega de produtos e serviços de qualidade, precisam receber informações que lhes permitam compreender e aceitar seus papéis individuais e coletivos nesse processo, revelando ser essencial o papel da comunicação interna como um instrumento de promoção da qualidade.

Estudos sobre o papel da comunicação interna como instrumento para a promoção da gestão da qualidade nas organizações ainda são escassos. $\mathrm{Na}$ literatura pesquisada, foram identificadas pesquisas no Brasil no ramo automotivo (CARDIA, 2004) e no ramo de serviços bancários (MATTOS, 2001). O presente trabalho pretende contribuir para aumentar a base de conhecimentos acerca deste tema.

Este estudo busca também compreender de que maneira a comunicação interna pode ser efetivamente utilizada como um instrumento de promoção da qualidade nas organizações. Inicialmente, o artigo traça um referencial teórico que busca contextualizar a comunicação como um dos principais instrumentos de marketing. Em seguida, evidencia a aplicação dos conceitos de marketing no ambiente interno das organizações, prática conhecida no Brasil como endomarketing. Finalmente, destaca o papel da comunicação interna como um instrumento de endomarketing que pode contribuir para a promoção da qualidade. Com a realização de um estudo de caso e tendo como objeto de estudo uma empresa global de comunicação, o artigo também identifica e propõe um conjunto de fatores determinantes para a efetiva utilização da comunicação interna como um instrumento de promoção da qualidade.

\section{A comunicação no contexto do marketing}

Embora a comunicação seja um fenômeno tão natural e inerente ao ser humano, percebe-se em torno dela um verdadeiro paradoxo. Se, por um lado, se trata de um tema multidisciplinar e que incentiva estudos em diversas áreas científicas, por outro, acaba sendo, na prática, negligenciada por alguns sistemas gerenciais, devido à própria naturalidade com que acontece entre os indivíduos dentro de uma organização.
Segundo Bordenave (1994), é por meio da comunicação que as pessoas compartilham experiências, ideias e sentimentos. Relacionando-se como seres interdependentes, os indivíduos influenciam-se mutuamente e, juntos, modificam a realidade na qual estão inseridos. Sem a comunicação, cada ser humano seria um mundo fechado em si mesmo, acrescenta aquele autor.

Para a gestão do marketing, a comunicação é muito mais do que um tema de fundamental relevância; ela é um dos pilares que sustentam o composto mercadológico. Kotler (1998) declara que, além de desenvolver um bom produto, definir para ele um preço atraente e distribuí-lo ao seu mercado-alvo, a gestão do marketing exige que as empresas se comuniquem efetivamente com seus diversos públicos. Assim, toda a organização assume inevitavelmente o papel de comunicadora e promotora, afirma o autor.

Utilizando a abordagem da Associação Americana de Marketing (American Marketing Association-AMA), Churchill Jr. e Peter (2005) explicam que a gestão do marketing é o processo de planejar e executar a concepção, o estabelecimento de preços, a distribuição e a promoção de ideias, bens e serviços, a fim de criar trocas que satisfaçam aos objetivos organizacionais e individuais. Tal definição tem como base um dos modelos mais tradicionais da teoria mercadológica, o dos 4 Ps do marketing - produto, preço, praça (distribuição) e promoção (comunicação) - elementos que em conjunto formam o composto de marketing (KOTLER, 2000). Grönroos (1994) define o composto de marketing como um conjunto de variáveis a serem gerenciadas pela função mercadológica. Mesmo apresentando críticas a respeito do clássico modelo dos 4 Ps, esse autor reconhece que, apesar de estar perdendo espaço para novos paradigmas, tal modelo ainda domina o pensamento, as pesquisas e a prática mercadológica.

Dentre os 4 Ps do composto de marketing, a promoção é também definida como composto promocional ou composto de comunicação (KOTLER, 2000), em que está inserida, entre outras variáveis, a propaganda. O composto promocional ou composto de comunicação reúne todos os modos pelos quais uma empresa busca comunicar-se com seus diversos públicos (KOTLER, 1998).

Assim como o marketing vem evoluindo significativamente desde que surgiu como um fenômeno da gestão de negócios (LINDGREEN et al. 2004), evoluíram com ele os seus modos de comunicação. Com o advento do endomarketing, por exemplo, a comunicação existente entre uma empresa e seus funcionários passou a ser um fator crítico de sucesso. No contexto do endomarketing, Inkotte (2000) define a comunicação como a "utilização de métodos, técnicas, recursos e meios para uma empresa dirigir-se e tornar-se receptiva ao seu público interno". 


\section{Marketing interno, endomarketing e comunicação interna}

Constata-se, em relação aos termos "marketing interno" e "endomarketing", que ainda existe certa divergência teórica tanto na literatura internacional quanto na nacional (BALLANTYNE, 2003; INKOTTE, 2000). No que se refere às obras internacionais, Ballantyne (2003) argumenta que existe ambiguidade em torno do conceito de marketing interno, apontando a inexistência de um modelo conceitual padrão. Em relação aos autores nacionais que abordam o tema endomarketing, Inkotte (2000) declara que a ausência de uma uniformidade teórica torna difícil uma análise comparativa entre suas obras.

$\mathrm{Na}$ literatura internacional, é possível identificar duas correntes de abordagens diferenciadas em relação ao conceito de marketing interno. A primeira delas adota como significado do termo a difusão da orientação de marketing para todos os indivíduos de uma organização. Já a segunda o conceitua como um conjunto de ações de marketing voltadas ao público interno de uma organização, no intuito de se conseguir de seus funcionários o comprometimento com os objetivos organizacionais.

Adotando a primeira linha de pensamento, Grönroos (1994) coloca que o marketing interno vem da necessidade de garantir suporte às pessoas da organização que, embora não sejam diretamente ligadas às funções de marketing, podem ser preparadas e informadas para melhor atender aos clientes. Com base no segundo tipo de abordagem, Mudie (2003) coloca que a ideia principal do marketing interno é a de que os funcionários de uma organização, ao serem tratados como clientes, tornam-se mais comprometidos, cooperativos e entusiasmados. A definição de marketing interno, em que se baseia esse autor, assemelha-se à apresentada pela Associação Americana de Marketing (American Marketing Association, 2006), que o define como "marketing voltado aos funcionários de uma organização para garantir que eles adotem de forma efetiva os programas e políticas organizacionais desejados".

A importância da comunicação interna é enfatizada entre os autores internacionais. Segundo Thornhill et al. (1996), toda organização busca implícita ou explicitamente o comprometimento de seus funcionários e um dos caminhos para alcançar tal objetivo é a comunicação interna. A investigação realizada por esses autores revela que existe uma significativa relação entre a forma com que uma organização interage e se comunica com seus funcionários e as atitudes e o comprometimento destes em relação a ela.

A efetividade da comunicação interna é especialmente requerida em cenários de mudança, que são frequentemente vivenciados pelas organizações (HEMAIS, 2005; KITCHEN; DALY,
2002; MATTOS, 2001). As pessoas de uma empresa devem ser encorajadas a participar das mudanças e melhorias dos processos. Essa participação requer a conscientização dos funcionários, por meio de treinamentos, palestras, campanhas de incentivo, comunicação interna e monitoramento por parte dos gestores, no dia a dia (ROCHA, 2007). Além das situações de mudança, Brum (2005) acrescenta que a comunicação interna também é importante nos momentos em que novos desafios são lançados aos funcionários como, por exemplo, quando uma empresa decide conquistar uma certificação de qualidade.

Entre as obras nacionais, o tema marketing interno é frequentemente abordado com o uso da palavra endomarketing, junção do prefixo de origem grega "endo", que quer dizer "ação ou movimento para dentro" (BRUM, 2005), com a palavra marketing, a qual já pode ser considerada, apesar da origem no idioma inglês, como um neologismo da língua portuguesa, por fazer parte do vocabulário trivial das pessoas. Para Inkotte (2000), no entanto, é necessário fazer uma distinção entre os conceitos de marketing interno e de endomarketing. O autor esclarece que, por meio do marketing interno, a empresa mobiliza seus funcionários para encantar o cliente externo, enquanto pelo endomarketing, a empresa é o próprio "produto", que precisa ser sempre melhorado para encantar o cliente interno. Assim, esse autor considera que a "utilização de instrumentos e conceitos do marketing voltados para o público interno de uma organização" é a definição que melhor se encaixa como significado de endomarketing.

Uma das convergências encontradas na literatura nacional é a ideia da comunicação interna como um dos principais instrumentos de endomarketing. Para Brum (2005), sendo a informação o "produto da comunicação interna", é também a maior estratégia de aproximação entre uma empresa e seus funcionários. Essa autora afirma que, por maiores que sejam os benefícios e incentivos oferecidos ao público interno, sem uma informação bem trabalhada, não existem funcionários motivados.

\section{Qualidade - conceitos e evolução}

A gestão da qualidade revelou seu dinamismo pelas transformações que foram ocorrendo em suas abordagens, desde seus primeiros movimentos até os atuais. De acordo com Ferreira (2004), "produzir qualidade" era uma função inicialmente restrita a um corpo de engenheiros e técnicos e, hoje, é uma responsabilidade coletiva. Essa mudança fez com que fosse acrescentada à imagem inicial da qualidade, construída sob a perspectiva das ciências exatas, uma abordagem predominantemente baseada nas ciências sociais, afirma o autor. Segundo a Sociedade Americana para a Qualidade (American Society for Quality, 2006), qualidade é um termo subjetivo para 
o qual são dadas muitas definições, mas que, em uma linguagem técnica, pode ter dois significados principais: a) as características de um produto ou serviço que sustentam sua habilidade de satisfazer às necessidades implícitas ou declaradas dos clientes; b) um produto ou serviço livre de defeitos.

Gaither e Frazier (2002) argumentam que a qualidade de produtos e serviços não é definida ou determinada pelas empresas, mas sim pelos seus clientes. Segundo esses autores, a qualidade é uma percepção do consumidor a respeito do nível em que suas expectativas são atendidas. Tal definição coincide com a de Feigenbaum (1961), para quem a qualidade está relacionada à intensidade com que um produto em uso virá ao encontro das expectativas dos clientes. Em uma abordagem distinta, Crosby (1988) defende a premissa de que a qualidade é um fator atingível, mensurável e lucrativo, podendo ser estabelecida desde que haja compromisso, compreensão, e que as pessoas estejam dispostas a trabalhar arduamente a seu favor. Dessa forma, resume o conceito de qualidade em "conformidade com os requisitos". Para Ishikawa (1993), o significado da palavra qualidade não pode ser restrito à qualidade do produto, devendo também ser compreendido em um sentido mais amplo, incluindo a qualidade da gestão. Segundo esse autor, a expressão "boa qualidade" deve ser associada à "melhor qualidade que uma organização pode produzir com sua tecnologia e capacidade atuais e que irá atender às expectativas dos consumidores". Sendo muitas as perspectivas que definem o termo qualidade, Garvin (1998) afirma ser arriscado adotar apenas uma abordagem como verdadeira.

Como função gerencial, a qualidade evoluiu e passou por gerações distintas, que foram chamadas por Garvin (1998) de "eras da qualidade": da inspeção, do controle estatístico da qualidade, da garantia da qualidade e da gestão estratégica da qualidade. $\mathrm{Na}$ era da gestão estratégica da qualidade, uma abordagem mais ampla começa a ser construída. Surge a percepção de que a qualidade não exige apenas um bom desempenho da função produção da empresa, e sim de todas as suas funções principais, suportadas pelas de apoio (GARVIN, 1998).

De acordo com Garbutt (1996), no intuito de gerir adequadamente suas atividades relativas à qualidade, muitas organizações passaram a adotar a filosofia da Gestão pela Qualidade Total, mundialmente conhecida como Total Quality Management (TQM). O TQM simboliza a "corrente hegemônica dos programas de qualidade empresariais, que envolvem não apenas a qualidade do produto e do processo, mas também uma determinada lógica de pensar a gestão e a organização da produção e do trabalho" (BIANCO; SALERNO, 2001).

Para que seja reconhecida como filosofia vigente em uma organização, o TQM é comumente operacionalizado por diversos sistemas e modelos de gestão da qualidade. Tais sistemas e modelos podem ser vistos como facilitadores da orientação para o TQM ou simplesmente como formas de se estruturar a gestão da qualidade. Sem dúvida, o mais popular entre eles é a série de normas ISO (International Organization for Standardization) 9000. Segundo Mello et al. (2002), a série ISO 9000 é um conjunto de normas e diretrizes utilizadas como base para o estabelecimento de sistemas de gestão da qualidade e tem obtido reputação mundial, desde a sua primeira publicação.

Outra iniciativa revolucionária, também vinculada à gestão da qualidade, foi a criação da metodologia Seis Sigma (Six Sigma), no final da década de 80 do último século. A ideia que deu origem ao Seis Sigma nasceu na Motorola, em uma época em que esta e outras empresas, especialmente as do setor manufatureiro, perceberam que sua competitividade estava ameaçada pela indústria japonesa (RAISINGHANI et al., 2005). Pinto et al. (2006) definem o Seis Sigma como um programa que tem como característica marcante o uso sistemático de ferramentas estatísticas, seguindo um ciclo conhecido como DMAIC (Define-MeasureAnalyse-Improve-Control), sigla que representa as etapas de definir, medir, analisar, melhorar e controlar.

Alternativa adicional para se estruturar a gestão da qualidade é a adesão aos modelos sugeridos para a conquista dos prêmios de qualidade existentes no mundo todo. De acordo com Mohr-Jackson (1998), um dos modelos mais adotados pelas empresas americanas para a implementação do TQM é o que reúne os critérios exigidos pelo Malcolm Baldrige National Quality Award (MBNQA), uma premiação que reconhece os melhores desempenhos relativos à qualidade nos Estados Unidos. No Brasil, existe o Prêmio Nacional de Qualidade (PNQ), que pode ser alcançado pelas empresas que optarem por seguir os critérios sugeridos pela Fundação Nacional da Qualidade em seu Modelo de Excelência da Gestão.

\section{Qualidade e comunicação}

A importância do papel exercido pela comunicação no processo de se promover a qualidade nas organizações é reconhecida por autores de ambas as áreas (BRUM, 2005; CARDIA, 2004; CROSBY, 1992; FEIGENBAUM, 1961; FERREIRA, 2004; THORNHILL et al. 1996; TROUTT et al. 1995; YAVAS, 1995). Um dos requisitos para a obtenção do comprometimento em relação à qualidade está ligado à efetividade dos sistemas de comunicação com os funcionários (THORNHILL et al. 1996). Segundo Ferreira (2004), a comunicação tem status de infraestrutura nos programas de qualidade e a efetividade de tais programas é diretamente proporcional às decisões tomadas na área de comunicação. Troutt et al. (1995) declaram que existe 
pouca chance de um programa de qualidade ser bem sucedido, se a comunicação não for considerada um elemento central em seu processo de implementação. Para Yavas (1995), antes que iniciativas de melhoria da qualidade sejam introduzidas em uma organização, é preciso que se promova, entre as pessoas, uma compreensão clara sobre o que significa qualidade e como ela é mensurada. Qualquer tentativa de melhoria da qualidade vai necessariamente envolver mudanças $\mathrm{e}$, consequentemente, podem ocorrer resistências, tanto por parte das gerências, quanto por parte da força de trabalho como um todo. Portanto, é importante que exista uma comunicação esclarecedora de dúvidas e que ajude na conquista do suporte e da confiança dos funcionários em relação à qualidade, conclui aquele autor.

Entre os autores clássicos da área da qualidade, Feigenbaum (1961) e Crosby (1992) merecem destaque pela forma com que abordam sobre a importância da comunicação no processo de se promover a qualidade nas organizações.

Feigenbaum (1961) enfatiza o valor da comunicação interna no processo de implementação de um programa de Controle da Qualidade Total ou Total Quality Control (TQC). O TQC é definido por esse autor como um sistema efetivo de desenvolvimento, manutenção e melhoria dos esforços de qualidade, exercido por vários grupos de uma organização, para elevar seus produtos e serviços aos mais altos níveis de economia que permitam a plena satisfação dos clientes.

Após uma ampla discussão sobre as técnicas e métodos de aplicação do TQC, Feigenbaum (1961) dá início à sua argumentação de que as mesmas técnicas e métodos, que fazem parte daquele sistema, não garantem por si só o seu sucesso, se não forem suportadas por uma atitude positiva em relação à qualidade, por parte das pessoas de uma organização. $\mathrm{O}$ autor continua seu raciocínio afirmando que tal atitude não é automaticamente desenvolvida com a simples instalação de um sistema de TQC, mas sim conquistada por meio de um processo responsável por "vender" a ideia que está por trás dele. $\mathrm{O}$ ato de "vender" o TQC que, nesse contexto, é obter aceitação, cooperação e participação das pessoas em relação ao sistema, requer comunicação.

Feigenbaum (1961) sugere que, após a aprovação de um programa de TQC, há uma sequência de iniciativas que devem ser tomadas para levar sua proposta à realidade operante na organização. Essas iniciativas estão ligadas à disseminação dos benefícios tangíveis do programa para toda a organização no intuito de que todos compreendam o real valor das atividades a ele relacionadas. São elas:

- Lançamento do programa pela alta gerência: sendo inevitável que surjam algumas resistências em relação ao programa, é altamente desejável que seja feita uma apresentação da verdadeira essência do TQC. A resistência é geralmente causada por falta de informação sobre os objetivos e procedimentos do programa. Dessa forma, a apresentação feita pela alta gerência deve esclarecer todos os pontos pertinentes e encorajar o entusiasmo de todos.

- Início das atividades projeto por projeto: selecionam-se alguns projetos que representem os primeiros passos do TQC. Sugere-se a escolha de dois ou três problemas de qualidade e, a partir da resolução destes, a escolha de novos projetos, permitindo-se assim que o programa como um todo vá evoluindo gradualmente e de forma mais adaptada às necessidades da organização.

- Resultados tangíveis: na medida em que um programa de controle da qualidade depende diretamente dos resultados que produz, é extremamente importante a utilização de meios adequados para que tais resultados sejam reportados. Os relatórios podem ser feitos por meio de periódicos mensais, sendo aconselhável a indicação dos esforços de cooperação realizados pelas pessoas.

- Comunicação e participação: essencial para uma genuína promoção do TQC é o desenvolvimento de um sentimento real de responsabilidade pelo programa, compartilhado por todos os membros da organização. Essa atitude favorável é alcançada pela comunicação dos objetivos da qualidade, feita a partir de diversos veículos e de formas variadas. Para tanto, indica-se a utilização do jornal da empresa, publicidade e artigos especiais sobre o controle da qualidade, quadros de avisos, apresentações, discussões e reuniões com os funcionários.

Crosby (1992) também reconhece a relevância da comunicação no processo de gerar compreensão e receptividade, por parte dos indivíduos, em relação à qualidade. Por meio de uma abordagem diferenciada, esse autor trata de diversos temas relacionados à qualidade, fazendo uso de uma analogia que compara a saúde organizacional à humana. Dessa forma, organizações com problemas de qualidade apresentam certas características que são chamadas de "sintomas" da falta de qualidade. Um dos ingredientes da "vacina" sugerida pelo autor é a comunicação. A "prevenção" é considerada um de seus princípios absolutos.

Crosby (1992) argumenta que, se todos os não cumprimentos dos requisitos estabelecidos para os produtos e serviços de uma organização têm uma causa, então também podem ser prevenidos. Assim, a organização que deseja evitar problemas de qualidade, fazer economia e manter seus clientes satisfeitos, precisa 
ser "vacinada". A "vacina" da qualidade, segundo o autor é composta pelos seguintes "ingredientes": integridade, sistemas, comunicação, operações e políticas.

Entre os ingredientes da "vacina" da qualidade, a comunicação é mais uma vez enfatizada, sendo definida como: informações sobre progressos e realizações de melhoria da qualidade são continuamente fornecidas aos funcionários; programas de reconhecimento são estabelecidos em todos os níveis; os membros da organização sabem identificar e comunicar sobre erros, desperdícios e oportunidades de melhoria. Especialmente sobre este elemento, Crosby (1992) acrescenta algumas sugestões:

- a comunicação que existe dentro do sistema de cultura de uma organização deve ser continuamente alimentada;

- todos os indivíduos devem estar atualizados sobre o status da melhoria da qualidade;

- cabe às equipes de melhoria da qualidade solicitar informes sobre suas realizações para alimentar os sistemas de comunicação;

- além do material de comunicação corporativo trivial, boletins de qualidade podem ser distribuídos e vídeos podem ser exibidos para que as melhorias alcançadas sejam divulgadas;

- programas de reconhecimento devem ser ajustados à mentalidade da organização;

- sistemas de comunicação devem ser estabelecidos para incentivar o contato entre os funcionários em geral e as lideranças da organização. Com este objetivo, formulários de autopreenchimento, uma linha telefônica exclusiva ou outros tipos de canais mais simples devem passar a fazer parte do funcionamento normal da organização; e

- canais de comunicação também devem ser abertos para os fornecedores. Esses, por sua vez, devem ser reconhecidos como uma extensão da própria empresa.

\section{Metodologia de pesquisa}

O estudo de caso, como definido por Yin (2005), foi o método adotado para o desenvolvimento desta pesquisa. O desenvolvimento deste estudo de caso baseou-se nas etapas sugeridas por Voss et al. (2002).

Primeiramente, desenvolveu-se uma estrutura conceitual, ilustrada pela Figura 1, que sintetiza e representa graficamente a possível dinâmica existente entre a comunicação interna e a gestão da qualidade em uma organização. A partir da estrutura conceitual proposta, foi estabelecida para esta pesquisa a seguinte questão inicial: como a comunicação interna pode ser utilizada como um instrumento de promoção da qualidade nas organizações?

Para esclarecer a questão inicial e garantir uma compreensão mais profunda dos processos de comunicação interna e de sua relevância para a promoção da qualidade, optou-se pela seleção de um caso único. Segundo Yin (2005), a escolha de uma unidade de análise única é justificável em algumas situações especiais, entre elas, quando o caso é considerado típico ou representativo.

O caso único selecionado para este estudo pode ser considerado típico ou representativo, porque permite a captura de circunstâncias e condições do dia a dia de uma instituição típica de um determinado setor (YIN, 2005). Os critérios de escolha e o perfil da instituição objeto deste estudo são paralelamente apresentados no Quadro 1.

Seguindo as etapas sugeridas por Voss et al. (2002), foi também desenvolvido um protocolo de pesquisa indicando, entre outros aspectos, os requisitos para a utilização dos roteiros desenvolvidos para conduzir as entrevistas pessoais (Anexos A, B e C).

Entre profissionais das áreas de comunicação interna e da qualidade, foram identificados informantes-chave, em diferentes níveis hierárquicos, habilitados para contribuir com dados pertinentes e necessários à investigação planejada, conforme apresentado no Quadro 2.

Para a condução desta pesquisa, foram utilizadas diferentes fontes de coleta de dados - entrevistas pessoais, documentação e observação direta -, respeitando, dessa forma, o recomendado uso da triangulação (YIN, 2005).

\section{Estudo de caso}

A organização escolhida para a condução deste estudo de caso é uma empresa global de comunicação.

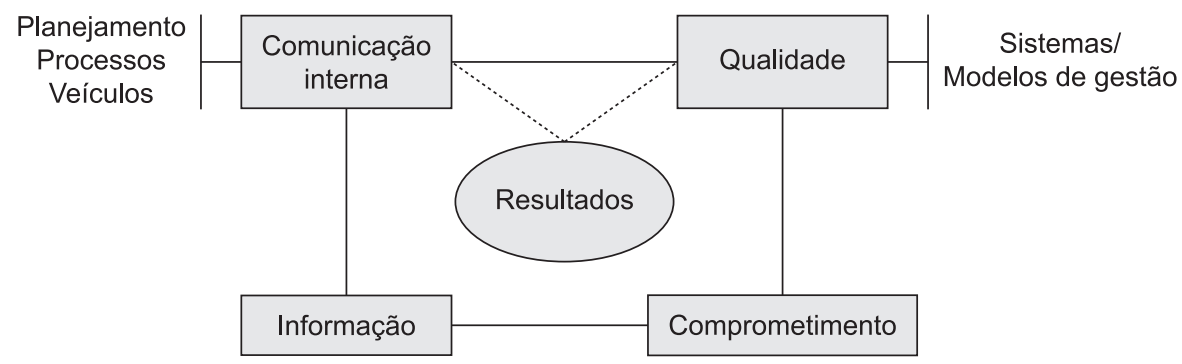

Figura 1. Estrutura conceitual proposta para a pesquisa. 
Quadro 1. Critérios de escolha e perfil da instituição objeto do estudo de caso.

\begin{tabular}{|ll|}
\hline \multicolumn{1}{|c|}{ Critérios de escolha } & \multicolumn{1}{c|}{ Perfil do objeto de estudo } \\
\hline - Empresa de grande porte, operante em setores de alta & - Empresa multinacional, com atuação de destaque \\
competitividade; & no setor de telecomunicações. No Brasil, opera com \\
& 7.500 funcionários; \\
- Certificada por alguma entidade mundialmente & - Empresa certificada pela TL 9000 desde 2001; e \\
reconhecida, que estabeleça um conjunto de padrões de & \\
qualidade; e & \\
- Ganhadora de alguma premiação importante & - Ganhadora do Malcolm Baldrige National Quality \\
relacionada à gestão da qualidade. & Award no ano de 2002. \\
\hline
\end{tabular}

Quadro 2. Informantes-chave participantes da pesquisa.

\begin{tabular}{|ll|}
\hline \multicolumn{1}{|c|}{ Funções entrevistadas } & \multicolumn{1}{c|}{ Justificativa de escolha dos informantes privilegiados } \\
\hline $\begin{array}{l}\text { Analista de Comunicação Interna } \\
\text { (Programa Suply Chain) }\end{array}$ & $\begin{array}{l}\text { Profissional de comunicação interna responsável por atender } \\
\text { aos setores envolvidos no Programa Suply Chain, incluindo o } \\
\text { departamento da qualidade. }\end{array}$ \\
Gerente Nacional da Qualidade & $\begin{array}{l}\text { Gerente de nível sênior, responsável pela gestão da qualidade em } \\
\text { nível nacional e a quem se reportam seis outros gerentes de segmentos } \\
\text { distintos da área da qualidade. }\end{array}$ \\
& $\begin{array}{l}\text { Gerente responsável pela qualidade nas linhas produtivas da empresa. } \\
\text { O segmento da qualidade da manufatura abriga o maior número de } \\
\text { profissionais do setor da qualidade. }\end{array}$ \\
$\begin{array}{l}\text { Supervisor da Qualidade } \\
\text { (Customer Quality Assurance - CQA) }\end{array}$ & $\begin{array}{l}\text { Responsável pela supervisão direta de quarenta e sete profissionais de } \\
\text { nível operacional, na área denominada de Customer Quality Assurance } \\
\text { (CQA). É funcionário da empresa há dez anos. }\end{array}$ \\
\hline
\end{tabular}

Fornece produtos e soluções de mobilidade, que atendem aos mercados de comunicação pessoal, corporativo e governamental. Entre os produtos e serviços oferecidos pela empresa estão: telefones celulares, telefones sem fio, rádios bidirecionais, soluções para os mercados de banda larga, TV a cabo e automotivo, entre outros.

Sediada nos Estados Unidos da América (EUA), a empresa pesquisada opera comercialmente em todos os continentes, possuindo unidades industriais em diferentes países. As operações industriais da empresa no Brasil são atualmente abrigadas em um Campus Industrial e Tecnológico, situado no interior do Estado de São Paulo, onde esta pesquisa foi desenvolvida. Na capital do mesmo Estado, a empresa possui também um escritório administrativo.

No intuito de manter o foco estabelecido para esta pesquisa - a comunicação interna como instrumento de promoção da qualidade -, procurou-se descrever a empresa objeto deste estudo com maior ênfase em suas estruturas de comunicação interna e de gestão da qualidade para que, posteriormente, a dinâmica entre essas duas funções organizacionais fosse analisada de forma coerente com a investigação proposta.

\subsection{Comunicação interna - estrutura e veículos}

O departamento de comunicação interna é considerado, na empresa pesquisada, um setor que presta serviços ou dá suporte a todos os seus negócios, recebendo a denominação de shared services, que significa serviços compartilhados.

A estrutura desse departamento reúne profissionais que atuam em duas frentes principais: corporativa e supply chain (cadeia de suprimentos).

A área corporativa é responsável pela comunicação de todos os programas que abrangem a organização como um todo, enquanto a área de comunicação ligada ao Programa Supply Chain atende aos setores diretamente ligados a este programa, incluindo o setor da qualidade. O departamento de comunicação interna realiza um planejamento anual de comunicação, que prevê os programas trivialmente realizados durante esse período. Além desses programas regulares, muitas outras ações de comunicação interna são implementadas no dia a dia da empresa, de acordo com as necessidades dos demais setores.

Entre os principais veículos de comunicação interna, utilizados pela empresa, estão:

- Comunicado eletrônico diário: destinado a transmitir mensagens diárias, prioritariamente ao 
público que possui acesso ao correio eletrônico. Ocasionalmente, quando se trata de uma mensagem de interesse geral, ela também pode ser impressa e fixada nos quadros de avisos.

- Jornal interno: distribuído mensalmente, nas versões impressa e eletrônica, costuma cobrir acontecimentos marcantes, ocorridos nesse período.

- Quadros de avisos: com atualização semanal, trata-se de um veículo mais direcionado ao público de operadores.

- Reunião geral trimestral: trata-se de um evento destinado à partilha de resultados, metas, estratégias e outros temas relevantes para a informação e o engajamento dos funcionários. Embora direcionado, prioritariamente, aos profissionais dos setores administrativos, esse evento também reúne funcionários ligados à operação, para os quais é dada a responsabilidade de transmitir as principais informações apresentadas ao público de operadores. Atualmente, sessenta operadores também são convidados a participar da reunião geral trimestral.

- Banners, faixas e painel eletrônico: utilizados para transmitir mensagens mais rápidas, circunstanciais ou emergenciais.

\subsection{Qualidade - estrutura e gestão}

O departamento da qualidade é composto por aproximadamente 200 pessoas. Esse número flutua de acordo com a rotatividade de funcionários temporários que trabalham nesse setor. O departamento possui um gerente sênior, responsável pela gestão geral da qualidade em nível nacional, para quem se reportam outros seis gerentes, alocados em frentes distintas (introdução de novos produtos; manufatura; programação, embalagens e entregas; sistemas da qualidade; atendimento a clientes; escritórios de projetos seis sigma).

A empresa é certificada e adota mundialmente um sistema de gestão da qualidade baseado no conjunto normativo TL9000. Paralelamente, o Seis Sigma é considerado um dos principais modelos de gestão da qualidade, que vigoram na empresa em nível global. O modelo recebeu, na empresa, o nome de Digital Six Sigma, após ter sido revitalizado pela incorporação de variadas ferramentas de informática.

"Diversos outros programas têm sido implementados, não apenas para garantir a melhoria da qualidade como também para buscar a excelência dos processos", explica o gerente nacional da qualidade. Dois desses programas merecem grande destaque:
- Programa QVS (Quality Vital Sign - Sinal Vital da Qualidade): com o propósito de melhorar a "saúde" corporativa, o programa busca o engajamento e o comprometimento da alta liderança em relação à qualidade, acreditando que essa postura favorável, por parte dos líderes, acaba por ser disseminada para os demais níveis da organização.

- Programa QIQ (Quality Intelligence Quoeficient Coeficiente de Inteligência da Qualidade): tem o objetivo de desenvolver competências e melhorar o conhecimento das pessoas da empresa em relação à qualidade, por meio de treinamentos em todos os níveis da organização.

Os programas QVS e QIQ fazem parte de um pacote mundial de programas da qualidade. Uma característica importante da gestão da qualidade na empresa é que ela recebe um direcionamento global, existindo inclusive a figura de uma liderança mundial da qualidade.

Todos os sistemas, modelos e programas da qualidade, que são definidos no nível mundial, são também adotados pela planta brasileira, o que não impede que iniciativas locais também possam ser realizadas. (Gerente da qualidade da manufatura).

\subsection{Dinâmica entre os setores de comunicação interna e da qualidade}

O setor de comunicação interna realiza programas ou ações de comunicação para o setor da qualidade apenas mediante a solicitação deste último. Nesse contexto, o setor de comunicação interna frequentemente desenvolve cartilhas, materiais informativos, peças de comunicação que dão suporte aos programas de qualidade, campanhas de conscientização sobre a melhoria da qualidade e outras ações que possam ser demandadas por aquele setor, no intuito de divulgar informações importantes, em diversas ocasiões.

"Quando uma auditoria da qualidade está para ser realizada na empresa, é a área de comunicação interna que faz a sua divulgação aos funcionários, anunciando que a auditoria estará acontecendo e incentivando as pessoas a se prepararem para tal desafio", explica a analista de comunicação interna.

Outro tema relacionado à qualidade, significativamente explorado dentro da pauta de comunicação interna da empresa, é o Digital Six Sigma. A empresa promove, anualmente, uma exposição local de projetos desenvolvidos por essa metodologia. Os melhores projetos são selecionados para participar de uma outra exposição que acontece em nível global. Esses eventos são anunciados por diferentes ações e veículos de comunicação interna. Os projetos vencedores e os nomes de seus responsáveis também são divulgados. 
É função do setor de comunicação interna desenvolver e implementar ações que venham ao encontro dos objetivos de comunicação do setor da qualidade. Cabe ao departamento da qualidade definir o tema que deverá ser trabalhado, para que a melhor solução de comunicação e seus respectivos materiais sejam então desenvolvidos pelo setor de comunicação interna.

Quando o objetivo é falar sobre qualidade com o público interno, todos os instrumentos e veículos de comunicação disponíveis na empresa são passíveis de utilização. A definição de quais instrumentos e veículos serão os mais adequados para transmitir uma mensagem do setor da qualidade dependerá do tema e do segmento do público interno que está sendo focado.

Não há um processo diferente ou específico para o atendimento do setor da qualidade, embora existam técnicas e recursos mais adequados para tratar de seus temas em algumas circunstâncias. Como exemplo, pode-se citar o uso intensivo de recursos visuais para falar de qualidade com o público de operadores. (Analista de comunicação interna).

De acordo com o gerente nacional da qualidade, as ações de comunicação interna devem ser frequentes, para que se alcance uma efetiva promoção da qualidade. "As pessoas somente passam a acreditar e a aderir à cultura da qualidade se existe uma comunicação constante nesse sentido". Confirmando tal observação, o gerente da qualidade da manufatura afirma que "a promoção da qualidade requer que estejamos sempre falando sobre ela e que a gerência esteja sempre demonstrando o quanto ela é importante".

Iniciativas de comunicação interna também são implementadas para falar de resultados. Para o gerente nacional da qualidade, "sempre que se realizam esforços de comunicação para que os funcionários melhorem seu comprometimento com a qualidade, esse ciclo precisa ser fechado com a divulgação dos resultados alcançados, sejam eles positivos ou negativos".

\subsection{Contribuição da comunicação interna como instrumento de promoção da qualidade}

A contribuição da comunicação interna no processo de se promover a qualidade na organização é reconhecida por todos os informantes-chave que participaram da pesquisa, porém sob diferentes pontos de vista.

De acordo com a analista de comunicação interna, os programas e ações de comunicação são de grande importância em diversos contextos, inclusive quando o intuito é o de promover o comprometimento com a qualidade. "Acredito que o conhecimento dos fatos promove maior comprometimento das pessoas e que os resultados da qualidade podem ser afetados positivamente".

Para o gerente nacional da qualidade, a contribuição da comunicação interna, como instrumento de promoção da qualidade, é ainda mais valorizada.

A comunicação interna é um instrumento fundamental para a divulgação de vários aspectos relacionados à qualidade, desde os valores organizacionais até o papel de cada indivíduo no alcance dos melhores resultados e da satisfação dos clientes. (Gerente nacional da qualidade).

É unânime, entre os profissionais do setor da qualidade, a percepção de que, embora seja grande a contribuição da comunicação interna para se promover a qualidade na organização, faz-se necessário que esse processo seja complementado pelo fator "atitude", por parte das lideranças.

Toda comunicação destinada a promover a qualidade deve ser coerente ou reforçada pelas atitudes e decisões das lideranças. Em momentos de crise, por exemplo, se os funcionários da empresa percebem que as lideranças tomam decisões que privilegiam a qualidade, em detrimento dos custos, verificarão que os princípios e valores anteriormente comunicados são realmente observados na prática. (Gerente nacional da qualidade).

Acredito que a comunicação interna afeta positivamente os resultados da qualidade, mas não somente ela. Quando se faz uma comunicação em favor da qualidade, é necessário que isso seja reforçado pelas ações dos supervisores imediatos e das lideranças, mostrando que aquilo é realmente importante. (Gerente da qualidade da manufatura).

Alguns veículos de comunicação interna são avaliados como mais eficientes em relação aos demais. Dentre eles, destacam-se o jornal interno e folhetos. "Os veículos de comunicação interna mais efetivos são aqueles que permanecem com os funcionários, tais como o jornal interno, folhetos e outros", observa o gerente da qualidade da manufatura.

A comunicação face a face entre lideranças e subordinados também é vista como indispensável dentro do processo de comunicação interna como um todo. Segundo o supervisor da qualidade, as reuniões realizadas com os operadores são bastante efetivas. Ele declara que "essas reuniões têm bastante impacto, porque é feita uma pausa na rotina dos operadores para se falar, de forma focada, sobre qualidade".

As evidências de que as iniciativas de comunicação interna afetam positivamente a qualidade na organização podem ser traduzidas nos próprios resultados do setor da qualidade.

Sempre que se realiza uma campanha de comunicação, no sentido de promover a qualidade, é possivel observar melhorias significativas dos seus resultados. Percebe-se também que a melhoria dos 
resultados está diretamente ligada ao comprometimento dos funcionários. (Gerente nacional da qualidade).

Segundo o supervisor da qualidade, "as evidências de melhorias existem, mas não é possível saber que porcentagem dessas melhorias pode ser atribuída à comunicação interna". Para o gerente nacional da qualidade, "a contribuição da comunicação interna na evolução positiva dos resultados da qualidade pode ser quantitativamente comprovada". Ele observa que um dos casos, que sustentam e exemplificam tal afirmação, está relacionado ao acompanhamento da redução dos índices internos de falhas. Após um período constatando que esses índices estavam sendo reduzidos em um nível inferior ao que havia sido estipulado como meta, a empresa decidiu realizar, no ano de 2006, uma campanha de comunicação focada em motivar os funcionários quanto ao seu alcance. Além da comunicação verbal, entre líderes e subordinados, diferentes veículos de comunicação interna foram utilizados para que a campanha se realizasse de forma efetiva e atingisse todos os públicos de interesse. Como resultado, os índices internos de falhas alcançaram a meta estabelecida, antes que o ano fosse encerrado.

\section{Análise dos resultados}

As evidências coletadas pelo estudo de caso sugerem que as práticas adotadas pela empresa, tanto em relação à gestão da qualidade quanto à comunicação interna, podem ser tomadas como referências valiosas por organizações que desejam investir na promoção da qualidade.

O estabelecimento e a manutenção de um sistema de gestão da qualidade certificado, com base em um conjunto normativo mundialmente reconhecido, como o da TL9000, a adoção de um modelo já validado por diversas organizações, como o Seis Sigma, a implementação de programas que incentivam o comprometimento com a qualidade, por parte das lideranças, e um maior conhecimento sobre qualidade, por parte do público interno em geral, todos esses elementos demonstram que a empresa pesquisada possui uma orientação para a qualidade total, nos moldes em que esse tema é abordado por diversos autores (BIANCO; SALERNO, 2001; GARBUTT, 1996; MOHR-JACKSON, 1998; PALMER; WILSON, 1995).

A disponibilidade de diferentes veículos de comunicação interna, a seleção e o uso integrado desses canais, em função do tema trabalhado e da audiência-alvo, são evidências observadas na empresa coerentes com recomendações de autores como Brum (2005) e Crosby (1992).

O reconhecimento de que a comunicação face a face, entre líderes e subordinados, também é de suma importância no processo de promoção da qualidade como um todo está de acordo com um dos posicionamentos de Feigenbaum (1961).

A comunicação interna dos resultados da qualidade não apenas se realiza na empresa, como também é percebida como um fator importante para o fechamento e a retomada do ciclo de promoção da qualidade. Essa é uma das propostas destacadas por Crosby (1992), Feigenbaum (1961) e também presente na norma ISO 9004:2000 (Associação Brasileira de Normas Técnicas, NBR ISO 9004, 2000, p.12).

Uma das observações de maior destaque, colocada pelos profissionais do setor da qualidade, é a de que toda ação de comunicação interna realizada para promover a qualidade deve ser reforçada pelo fator "atitude", por parte das lideranças. Essa percepção é comprovada por Thornhill et al. (1996), cuja pesquisa demonstrou que a comunicação efetiva deve ter consistência e credibilidade. Essa última dimensão, segundo aqueles autores, diz respeito à coerência entre a comunicação existente em uma empresa e o comportamento de suas lideranças. Palmer e Wilson (1995) também ressaltam a importância de uma postura gerencial coerente com aquilo que é comunicado. Para esses autores, os líderes nunca conseguirão convencer seus seguidores a respeito de suas filosofias se eles próprios não acreditarem nelas ou se estiverem dizendo algo e, em contrapartida, agindo de outra forma.

Sendo assim, com base nas declarações dos respondentes e na comparação delas com a literatura pesquisada, destacam-se os fatores que podem ser considerados determinantes para a utilização da comunicação interna no processo de se promover a qualidade nas organizações:

- Segmentação do público interno: os diferentes grupos de indivíduos que compõem o público interno de uma organização devem ser identificados, a partir de parâmetros coerentemente definidos. Esse processo deverá auxiliar na tomada de decisões relativas à linguagem utilizada e à seleção de veículos de comunicação interna.

- Coerência da linguagem: a transmissão de mensagens destinadas à promoção da qualidade requer cuidados em relação à linguagem que será utilizada. Um mesmo tema, relacionado à qualidade, pode ser desenvolvido por meio de linguagens diferenciadas e customizadas em função de cada segmento do público interno.

- Utilização estratégica de recursos visuais: para falar de qualidade, especialmente com profissionais de nível operacional, o uso estratégico de recursos visuais, tais como cores, símbolos, sinalizações, personagens e outros, pode gerar maior interesse e facilitar 
a compreensão da mensagem, por parte deste público.

- Disponibilidade e seleção de veículos de comunicação interna: a promoção da qualidade pode ser favorecida em organizações que disponham e façam uso de variados veículos de comunicação interna. A seleção ou a combinação de diferentes veículos de comunicação interna deve ser feita de forma otimizada e integrada, considerando a audiência prevista, o tema em pauta e a prioridade da mensagem.

- Qualidade e estética dos materiais de comunicação interna: a qualidade também deve ser refletida nos materiais de comunicação interna utilizados por uma empresa. O zelo pela estética e pela atratividade desses materiais também pode ser considerado um fator que contribui para que as mensagens da qualidade sejam recebidas com maior interesse.

- Participação de profissionais da qualidade: é recomendável que haja participação de profissionais da qualidade no desenvolvimento de ações de comunicação interna, cujo propósito é falar de qualidade. As equipes da qualidade devem contribuir na definição clara do tema a ser trabalhado, na disponibilidade de informações precisas para a formatação das mensagens, na revisão e aprovação das soluções desenvolvidas.

- Frequência: para potencializar a promoção da qualidade, os esforços de comunicação interna devem ser permanentes, no intuito de fazer com que a qualidade seja reconhecida e incorporada como um valor organizacional.

- Equilíbrio dos fluxos de comunicação interna: ideias valiosas para a promoção da qualidade também podem partir de funcionários da base da hierarquia organizacional. Para que essas ideias se tornem conhecidas e oportunamente aproveitadas, é preciso que sejam estabelecidos canais de comunicação interna, que incentivem e facilitem a manifestação das pessoas em favor da promoção da qualidade, tornando mais equilibrados os fluxos de comunicação.

- Comunicação de resultados: qualquer esforço de comunicação interna realizado para promover a qualidade em uma organização deve incluir a divulgação dos resultados alcançados, quer positivos quer negativos, para que o ciclo de promoção da qualidade seja encerrado e, ao mesmo tempo, retomado.
- Comunicação pessoal: o processo de promoção da qualidade, como um todo, também deve considerar a importância da comunicação pessoal, entre lideranças e funcionários em geral. Reuniões destinadas à discussão exclusiva de temas relacionados à qualidade e outras iniciativas de caráter dinâmico e interativo, são exemplos de oportunidades de comunicação pessoal, indispensável para a promoção da qualidade.

- Mensuração da receptividade do público interno: para avaliar a efetividade dos esforços de comunicação interna, realizados em favor da promoção da qualidade, e garantir que esse processo seja continuamente melhorado, é importante que sejam estabelecidos instrumentos para mensurar a receptividade do público interno, em relação às mensagens da qualidade. Um dos caminhos para medir e analisar essa receptividade é a realização de pesquisas internas.

- Comunicação reforçada pelo fator atitude: a credibilidade e a sustentabilidade de qualquer iniciativa de comunicação interna, implementada para promover a qualidade em uma organização, dependerão da coerência entre o que fora comunicado e as atitudes de suas lideranças. Se a postura gerencial não refletir o reconhecimento da qualidade como um princípio absoluto, toda comunicação realizada para promover a qualidade será vista apenas como discurso.

- Desenvolvimento de uma cultura da qualidade: os esforços de comunicação interna também devem ser direcionados ao incentivo do comprometimento, tanto das lideranças como dos funcionários em geral, em relação à qualidade, e que o conhecimento sobre a qualidade seja disseminado por meio de um enfoque educacional. O estabelecimento e a divulgação de uma política da qualidade são iniciativas fundamentais para que a qualidade seja promovida como parte da cultura organizacional.

- Compreensão da comunicação interna sob uma abordagem processual: todo esforço de comunicação interna realizado para promover a qualidade deve ser compreendido como um processo que exige planejamento, considerando a mensagem principal que se deseja transmitir, a audiência em foco, a seleção dos veículos de comunicação mais adequados, os resultados a serem alcançados, a métrica para avaliar a resposta do público alvo, os fatores críticos e o cronograma previsto. 


\section{Conclusão}

A combinação entre os fatores destacados na literatura científica e os apreendidos com o levantamento das práticas da empresa pesquisada permite a compreensão de como a comunicação interna pode ser utilizada como um instrumento de promoção da qualidade.

Conclui-se que, para que a comunicação interna seja efetivamente utilizada como um instrumento de promoção da qualidade, é preciso, em primeiro lugar, que sua contribuição, nesse mesmo sentido, seja reconhecida e valorizada tanto pelas lideranças da qualidade, como pelos profissionais de comunicação interna, envolvidos naquele processo.

Para tanto, os seguintes fatores identificados merecem ser destacados: segmentação do público interno, coerência da linguagem, utilização estratégica de recursos visuais, disponibilidade e seleção de veículos de comunicação interna, qualidade e estética dos materiais de comunicação interna, participação de profissionais da qualidade, frequência dos esforços de comunicação, equilíbrio dos fluxos de comunicação interna, comunicação de resultados, comunicação pessoal, mensuração da receptividade do público interno, comunicação reforçada pelo fator atitude, desenvolvimento de uma cultura da qualidade e a compreensão da comunicação interna sob uma abordagem processual.

Finalmente, considera-se que o presente trabalho atingiu seus objetivos e gerou uma contribuição científica para a base de conhecimento, identificando os fatores para a utilização efetiva da comunicação interna na promoção da qualidade em empresas de comunicação.

\section{Agradecimentos}

Os autores agradecem à FAPEMIG (processos EDT-538/07 e TEC-PPM-00043-08) pelos recursos fornecidos para o fomento de pesquisas, sem os quais a realização desta pesquisa não seria possível. Nosso muito obrigado também à empresa pesquisada e aos seus colaboradores por permitir o acesso aos dados que contribuíram para a consecução do presente trabalho.

\section{Referências}

AMERICAN MARKETING ASSOCIATION - AMA. Dictionary of marketing terms. Disponível em: $<$ http://www.marketingpower.com>. Acesso em: 30 de setembro de 2006.

AMERICAN SOCIETY FOR QUALITY - ASQ. Learn about quality: basic concepts. Disponível em: <http:// www.asq.org/learn-about-quality/basic-concepts.html>. Acesso em: 15 de outubro de 2006.

ASSOCIAÇÃO BRASILEIRA DE NORMAS TÉCNICAS ABNT. NBR ISO 9004. Sistemas de gestão da qualidade: diretrizes para melhorias de desempenho. Rio de Janeiro, 2000.

BALLANTYNE, D. A relationship-mediated theory of internal marketing. European Journal of Marketing, v. 37, n. 9, p. 1242-1260, 2003.

BIANCO, M. F.; SALERNO, M. S. Como o TQM opera e o que muda nas empresas? Um estudo a partir de empresas líderes no Brasil. Gestão \& Produção, v. 8, n. 1, p. 56-67, 2001.

BORDENAVE, J. E. D. O que é comunicação. 20 ed. São Paulo: Brasiliense, 1994.

BRUM, A. M. Endomarketing como estratégia de gestão: encante seu cliente interno. 3 ed. Porto Alegre: L\&PM, 2005.

CARDIA, A. N. Comunicação interna e gestão da qualidade total: o caso Volkswagen- unidade Resende. Revista Produção, v. 14, n. 2, p. 6-17, 2004.

CHURCHILL JUNIOR, G. A.; PETER, J. P. Marketing criando valor para os clientes. 2 ed. São Paulo: Saraiva, 2005.

CROSBY, P. B. Qualidade é investimento. 3 ed. Rio de Janeiro: José Olympio, 1988.

CROSBY, P. B. Qualidade sem lágrimas: a arte da gerência descomplicada. 4 ed. Rio de Janeiro: José Olympio, 1992.

FEIGENBAUM, A. V. Total quality control. New York: McGraw Hill Book Company, 1961.

FERREIRA, A. A. Comunicação para a qualidade. Rio de Janeiro: Qualitymark, 2004.

GAITHER, N.; FRAZIER, G. Operations Management 9 ed. Austrália: South Western, 2002.

GARBUTT, S. The transfer of TQM from industry to education. Education \& Training, v. 38, n. 7, p. 16-22, 1996.

GARVIN, D. A. Gerenciando a qualidade: a visão estratégica e competitiva. Rio de Janeiro: Qualitymark, 1998.

GRÖNROOS, C. From marketing mix to relationship marketing: towards a paradigm shift in marketing. Management Decision, v. 32, n. 2, p. 4-20, 1994.

HEMAIS, M. W. Marketing interno no Brasil: estudos de caso em empresas de serviços. 2005. Dissertação (Mestrado em Administração de Empresas) - Pontifícia Universidade Católica do Rio de Janeiro - PUC, Rio de Janeiro.

INKOTTE, A. L. Endomarketing: elementos para a construção de um marco teórico. 2000. Dissertação (Mestrado em Engenharia de Produção) - Universidade Federal de Santa Catarina - UFSC, Florianópolis.

ISHIKAWA, K. Introduction to quality control. 3 ed New York: Quality Resources, 1993.

KITCHEN, P. F.; DALY, F. Internal communication during change management. Corporate Communication: An International Journal, v. 7, n. 1, p. 46-53, 2002.

KOTLER, P. Administração de marketing: análise, planejamento, implementação e controle. 5 ed. São Paulo: Atlas, 1998.

KOTLER, P. Marketing Management: millenium edition. 10 ed. New Jersey: Prentice Hall, 2000.

LINDGREEN, A.; PALMER, R.; VANHAMME, J. Contemporary marketing practice: theoretical proposition 
and practical implications. Marketing Intelligence $\boldsymbol{\&}$ Planning, v. 22, n. 6, p. 673-692, 2004.

MATTOS, M. Comunicação interna e mudança comportamental em instituições bancárias: um estudo de caso. 2001. Dissertação (Mestrado em Engenharia de Produção) - Universidade Federal de Santa Catarina UFSC, Florianópolis.

MELLO, C. H. P. et al. ISO 9001:2000: sistema de gestão da qualidade para operações de produção e serviços. São Paulo: Atlas, 2002.

MOHR-JACKSON, I. Managing a total quality orientation: factors affecting customer satisfaction. Industrial Marketing Management, v. 27, p. 109-125, 1998.

MUDIE, P. Internal customer: by design or by default. European Journal of Marketing, v. 37, n. 9, p. 1261-1276, 2003.

NAVEH, E.; MARCUS, A. Achieving competitive advantage through implementing a replicable management standard: installing and using ISO 9000. Journal of Operations Management, v. 24, n. 1, p. 1-26, 2005.

PALMER, R.; WILSON, J. P. Maintaining the energy for commitment to quality. Training for Quality, v. 3, n. 2, p. 9-13, 1995.

PINTO, S. H. B.; CARVALHO, M. M.; HO, L. L. Implementação de programas de qualidade: um survey em empresas de grande porte no Brasil. Gestão \& Produção, v. 13, n. 2, p. 191-203, 2006.
RAISINGHANI, M. S. et al. Six sigma: concepts, tools, and applications. Industrial Management \& Data Systems, v. 105, n. 4, p. 491-505, 2005.

ROCHA, T. V. Marketing de relacionamento e competitividade no mercado empresarial: um estudo de caso em uma empresa multinacional agroquímica. 2007. Tese (Doutorado em Administração) - Universidade de São Paulo - USP, São Paulo.

STEVENSON, T. H.; BARNES, F. C. What industrial marketers need to know about ISO 9000 certification: a review, update, and integration with marketing. Industrial Marketing Management, v. 31, p. 695-703, 2002.

THORNHILL, A.; LEWIS, P.; SAUNDERS, M. N. K. The role of employee communication in achieving commitment and quality in higher education. Quality Assurance in Education, v. 4, n. 1, p. 12-20, 1996.

TROUTT, M. D.; PONCE DE LEON, J. A.; BATEMAN, D. N. The interplay between quality improvement principles and the employee communication process. Benchmarking for Quality Management \& Technology, v. 2, n. 4, p. 51-60, 1995.

VOSS, C.; TSIKRIKTSIS, N.; FROHLICH, M. Case research in operations management. International Journal of Operations Management, v. 22, n. 2, p. 196-219, 2002.

YAVAS, B. F. Employee perceptions of quality: survey results. International Journal of Quality \& Reliability Management, v. 12, n. 5, p. 8-17, 1995.

YIN, R. K. Estudo de caso: planejamento e métodos. 3 ed. Porto Alegre: Bookman, 2005. 


\section{Anexo A - Roteiro para entrevista com profissional de comunicação interna}

\begin{tabular}{|c|c|c|}
\hline Aspectos abordados & Roteiro de tópicos principais & Questões para monitoramento \\
\hline Comunicação Interna & $\begin{array}{l}\text { - Estrutura } \\
\text { - Missão } \\
\text { - Planejamento, } \\
\quad \text { processos, veículos } \\
\text { - Segmentação do público interno } \\
\text { - Fluxos de comunicação }\end{array}$ & $\begin{array}{l}\text { - Como é a estrutura de comunicação interna da } \\
\text { empresa? } \\
\text { - Qual é a missão do departamento de comunicação } \\
\text { interna? } \\
\text { - Como são planejadas as ações de comunicação } \\
\text { interna? } \\
\text { - Quais são os processos e veículos utilizados para se } \\
\text { fazer comunicação interna na empresa? } \\
\text { - Existem ações de comunicação interna diferenciadas } \\
\text { para segmentos distintos do público interno da } \\
\text { organização? } \\
\text { - Os fluxos de comunicação são bidirecionais } \\
\text { ou ocorrem apenas de forma descendente (das } \\
\text { lideranças para os funcionários em geral)? }\end{array}$ \\
\hline $\begin{array}{l}\text { Comunicação } \\
\text { Interna \& Qualidade }\end{array}$ & $\begin{array}{l}\text { - Interfaces } \\
\text { - Processos e veículos específicos } \\
\text { - Receptividade do } \\
\text { público interno }\end{array}$ & $\begin{array}{l}\text { - Existe interface entre o departamento de } \\
\text { comunicação interna e o de qualidade? Como ela } \\
\text { acontece? } \\
\text { - Quais são os processos e veículos utilizados para a } \\
\text { transmissão de mensagens que se encaixam dentro } \\
\text { do escopo da gestão da qualidade? } \\
\text { - Como pode ser descrito o processo de comunicação } \\
\text { interna quando utilizado para promover a qualidade } \\
\text { entre os funcionários da organização? } \\
\text { - Como as mensagens relacionadas à qualidade são } \\
\text { recebidas pelo público interno? } \\
\text { - Existem canais para feedback dos funcionários em } \\
\text { relação às mensagens da gestão da qualidade? }\end{array}$ \\
\hline Resultados & $\begin{array}{l}\text { - Relevância da } \\
\text { comunicação interna } \\
\text { - Qualidade como cultura } \\
\text { comprometimento } \\
\text { - Evidências }\end{array}$ & $\begin{array}{l}\text { - Como pode ser avaliada a relevância da } \\
\text { comunicação interna como instrumento de } \\
\text { promoção da qualidade na empresa? } \\
\text { - Como a qualidade tem sido promovida como parte } \\
\text { da cultura organizacional? } \\
\text { - Que evidências revelam que os funcionários se } \\
\text { tornam mais comprometidos em relação à qualidade } \\
\text { quando são implementadas ações de comunicação } \\
\text { interna nesse sentido? }\end{array}$ \\
\hline
\end{tabular}




\section{Anexo B - Roteiro para entrevista com profissional do setor da qualidade (nível gerencial)}

\begin{tabular}{|c|c|c|}
\hline Aspectos abordados & Roteiro de tópicos principais & Questões para monitoramento \\
\hline Qualidade & $\begin{array}{l}\text { - Estrutura } \\
\text { - Rotinas } \\
\text { - Sistemas, modelos e } \\
\text { programas de gestão } \\
\text { - Cultura } \\
\text { - Resultados }\end{array}$ & $\begin{array}{l}\text { - Como está estruturado o departamento da } \\
\text { qualidade e quais as suas principais rotinas? } \\
\text { - Quais são os sistemas, modelos e programas de } \\
\text { gestão da qualidade adotados pela empresa? } \\
\text { - Que sistemas ou modelos de gestão da } \\
\text { qualidade operam em todas as unidades da } \\
\text { empresa em nível mundial? } \\
\text { - Até que ponto existe uma cultura da qualidade } \\
\text { disseminada para além do departamento } \\
\text { responsável? } \\
\text { - Como podem ser avaliados os resultados que } \\
\text { têm sido alcançados pela gestão da qualidade } \\
\text { operante na empresa? }\end{array}$ \\
\hline $\begin{array}{l}\text { Qualidade \& } \\
\text { Comunicação Interna }\end{array}$ & $\begin{array}{l}\text { - Promoção da qualidade } \\
\text { - Contribuição da } \\
\text { comunicação interna } \\
\text { - Receptividade do } \\
\text { público interno }\end{array}$ & $\begin{array}{l}\text { - Como você acredita que a qualidade pode ser } \\
\text { efetivamente promovida no ambiente interno da } \\
\text { organização? } \\
\text { - Como você avalia a contribuição de programas } \\
\text { e ações de comunicação interna para a } \\
\text { promoção da qualidade na organização? } \\
\text { - Em que situações e com que frequência o } \\
\text { departamento de comunicação interna é } \\
\text { acionado para transmitir mensagens específicas } \\
\text { do setor de qualidade? } \\
\text { - Quais são as ações e veículos de comunicação } \\
\text { interna que podem ser considerados como } \\
\text { mais efetivos na promoção da qualidade na } \\
\text { organização? } \\
\text { - Como as mensagens relacionadas à qualidade } \\
\text { são recebidas pelo público interno? }\end{array}$ \\
\hline Resultados & $\begin{array}{l}\text { - Evidências } \\
\text { - Comprometimento } \\
\text { - Comunicação de resultados. }\end{array}$ & $\begin{array}{l}\text { - Que evidências podem demonstrar que } \\
\text { os resultados da qualidade são afetados } \\
\text { positivamente por ações de comunicação } \\
\text { interna? } \\
\text { - Que evidências demonstram que os } \\
\text { funcionários se tornam mais comprometidos } \\
\text { em relação à qualidade quando são } \\
\text { implementadas ações de comunicação interna } \\
\text { nesse sentido? } \\
\text { - Como os resultados da qualidade (positivos } \\
\text { ou negativos) são transmitidos no intuito de } \\
\text { gerar maior comprometimento por parte dos } \\
\text { funcionários? }\end{array}$ \\
\hline
\end{tabular}




\section{Anexo C - Roteiro para entrevista com profissional do setor da qualidade (nível de supervisão)}

\begin{tabular}{|c|c|c|}
\hline Aspectos abordados & Roteiro de tópicos principais & Questões para monitoramento \\
\hline Qualidade & $\begin{array}{l}\text { - Rotinas } \\
\text { - Conhecimento } \\
\text { - Comprometimento } \\
\text { - Resultados }\end{array}$ & $\begin{array}{l}\text { - Quais são as principais rotinas do departamento } \\
\text { da qualidade? } \\
\text { - Como você avalia o nível de conhecimento da } \\
\text { população de operadores em relação à qualidade } \\
\text { (sistemas, modelos, programas, ferramentas, } \\
\text { métricas)? } \\
\text { - Como você percebe o grau de comprometimento } \\
\text { dos operadores em relação à qualidade? } \\
\text { - Como você avalia os resultados que têm sido } \\
\text { alcançados pela gestão da qualidade operante na } \\
\text { empresa? }\end{array}$ \\
\hline $\begin{array}{l}\text { Qualidade \& } \\
\text { Comunicação Interna }\end{array}$ & $\begin{array}{l}\text { - Promoção da qualidade - } \\
\text { contribuição da } \\
\text { comunicação interna } \\
\text { - Programas e veículos de } \\
\text { comunicação interna } \\
\text { - Papel da liderança } \\
\text { - Receptividade do } \\
\text { público interno }\end{array}$ & $\begin{array}{l}\text { - Como a qualidade tem sido promovida junto aos } \\
\text { operadores? } \\
\text { - Como você avalia a contribuição de programas e } \\
\text { ações de comunicação interna para a promoção } \\
\text { da qualidade entre os operadores? } \\
\text { - Que programas, ações e veículos de } \\
\text { comunicação interna podem ser considerados } \\
\text { como mais efetivos para se promover a } \\
\text { qualidade entre os operadores? } \\
\text { - Qual o papel da liderança no processo de } \\
\text { promoção da qualidade? } \\
\text { - Como as mensagens relacionadas à qualidade } \\
\text { têm sido recebidas pelo público de operadores? } \\
\text { - Como você avalia os canais de feedback } \\
\text { disponibilizados para que os operadores se } \\
\text { manifestem sobre as questões da qualidade? }\end{array}$ \\
\hline Resultados & $\begin{array}{l}\text { - Evidências } \\
\text { - Comprometimento } \\
\text { - Comunicação de resultados }\end{array}$ & $\begin{array}{l}\text { - Que evidências podem demonstrar que } \\
\text { os resultados da qualidade são afetados } \\
\text { positivamente por ações de comunicação } \\
\text { interna? } \\
\text { - Que evidências demonstram que os funcionários } \\
\text { se tornam mais comprometidos em relação à } \\
\text { qualidade quando são implementadas ações de } \\
\text { comunicação interna nesse sentido? } \\
\text { - Como os operadores recebem e reagem à } \\
\text { comunicação dos resultados da qualidade } \\
\text { (positivos ou negativos)? Cresce o } \\
\text { comprometimento após a comunicação de tais } \\
\text { resultados? }\end{array}$ \\
\hline
\end{tabular}

